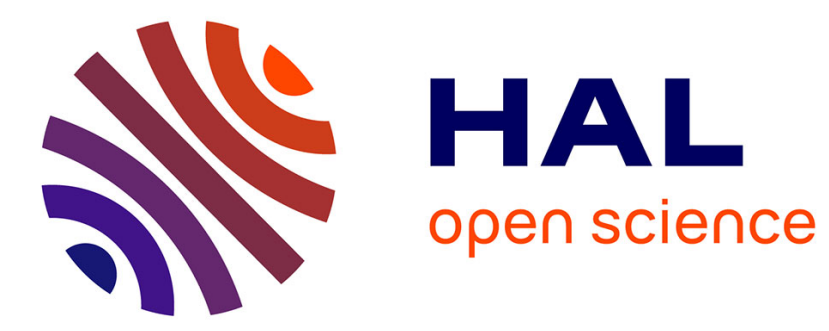

\title{
Anthropometric characterization of the child's liver
}

\author{
G. Pauleau, Baptiste Sandoz, L. Thollon, T. Serre, C. Brunet
}

\section{To cite this version:}

G. Pauleau, Baptiste Sandoz, L. Thollon, T. Serre, C. Brunet. Anthropometric characterization of the child's liver. Surgical and Radiologic Anatomy, 2010, 25p. 10.1007/s00276-010-0675-8 . hal00543247

\section{HAL Id: hal-00543247 \\ https://hal.science/hal-00543247}

Submitted on 15 Dec 2010

HAL is a multi-disciplinary open access archive for the deposit and dissemination of scientific research documents, whether they are published or not. The documents may come from teaching and research institutions in France or abroad, or from public or private research centers.
L'archive ouverte pluridisciplinaire HAL, est destinée au dépôt et à la diffusion de documents scientifiques de niveau recherche, publiés ou non, émanant des établissements d'enseignement et de recherche français ou étrangers, des laboratoires publics ou privés. 


\section{Editorial Manager(tm) for Surgical and Radiologic Anatomy Manuscript Draft}

Manuscript Number: SARA-D-09-00367

Title: Anthropometric characterization of the child's liver

Article Type: Original Article

Keywords: liver; child; modeling; CT; growth

Corresponding Author: Mr. Baptiste Sandoz, MSc

Corresponding Author's Institution: Laboratory of Applied Biomechanics, UMRT 24 INRETS/Université de la Méditerranée

First Author: Ghislain Pauleau, MD

Order of Authors: Ghislain Pauleau, MD; Baptiste Sandoz, MSc; Lionel Thollon, PhD; Thierry Serre, PhD; Christian Brunet, MD

Abstract: Purpose: The major purpose of this retrospective study on twenty-five CT-scanners of children liver from 2 to 13 years old was to investigate the growth, morphologic variations and modifications of the liver position as a function of the children age. The objective was to characterize the 3D geometry of the child liver, which is still unknown.

Methods: 3D reconstruction of children liver was performed using the Mimics software. Measurements of volume (total liver and right lobe), distance between anatomic reference points and angles were realized. The liver position was determined with respect to the 11th thoracic vertebra.

Results: The liver growth monitoring shows that it is harmonious as for the volume relations between the right lobe and the left lobe but disharmonious as for the distance measures situated in relation to the falciform ligament. The liver position with respect to the vertebral column in the peritoneal cavity was unchanged during the liver growth.

Conclusion: The results obtained from this preliminary work give description of the child liver during growth and are of interest for the numerical modeling.

Surgical and Radiologic Anatomy, 2010

Copyright : @ Springer Verlag

DOI: $10.1007 / \mathrm{s} 00276-010-0675-8$

http://www.springerlink.com/content/100112/ 


\title{
Anthropometric characterization of the child's liver
}

\author{
Ghislain Pauleau ${ }^{1}$, Baptiste Sandoz ${ }^{2 *}$, Lionel Thollon ${ }^{2}$, Thierry Serre ${ }^{2}$, Christian Brunet ${ }^{2}$ \\ 1.Department of Digestive Surgery, Laveran Military Hospital, Blvd Laveran 13013 Marseille \\ BP 50, France. \\ 2. Laboratory of Applied Biomechanics, UMRT 24 INRETS/Université de la Méditerranée, \\ Faculté de Médecine Secteur Nord, Blvd. Pierre Dramard, 13916 Marseille cedex 20, France. \\ *Corresponding author \\ Email: baptiste.sandoz@,free.fr
}

\begin{abstract}
Purpose: The major purpose of this retrospective study on twenty-five CT-scanners of children liver from 2 to 13 years old was to investigate the growth, morphologic variations and modifications of the liver position as a function of the children age. The objective was to characterize the $3 \mathrm{D}$ geometry of the child liver, which is still unknown.

Methods: 3D reconstruction of children liver was performed using the Mimics ${ }^{\circledR}$ software. Measurements of volume (total liver and right lobe), distance between anatomic reference points and angles were realized. The liver position was determined with respect to the $11^{\text {th }}$ thoracic vertebra.

Results: The liver growth monitoring shows that it is harmonious as for the volume relations between the right lobe and the left lobe but disharmonious as for the distance measures situated in relation to the falciform ligament. The liver position with respect to the vertebral column in the peritoneal cavity was unchanged during the liver growth.
\end{abstract}

Conclusion: The results obtained from this preliminary work give description of the child liver during growth and are of interest for the numerical modeling.

Keywords: Liver, Child, Modeling, CT, Growth. 


\section{INTRODUCTION}

The knowledge of liver volume is of clinical relevance when determining graft size for transplantation and organ viability after resection. It is also important to know this volume and its variance in different populations for the prediction of hepatic drug clearance using physiologically based pharmacokinetic models [12]. Many models have been described to estimate liver volume, even in children, using various parameters such as the body surface area, size, weight, age and sexes [14]. However, the liver morphology and growth during health childhood were not yet studied at our knowledge.

Various numerical models of parts or whole human bodies used to predict the kinematic behaviour of the human body are of interest to define injury mechanisms caused by a car crash and thereby to improve the car user safety [7]. However, these models must be adapted for application to children since the physiological and morphological aspects between adults and children are relatively different.

The current children model conception realized from adult models using a linear scale seems to be not sufficiently accurate. Indeed, the children growth is a differential process among organ and body segments, and each of them enlarges at a specific speed. These particular patterns, applied to internal organs, imply that there is a possible evolution between each other [2]. For example, the liver weight, when compared to total body weight, changes along lifespan [6]. The liver morphology and physiology change also between foetal and neonatal periods. The foetal liver is symmetric, i.e., the left and right hepatic lobes have nearly the same volume. This physiologic difference between the two liver lobes is the consequence of the blood circulation in the foetal liver, which is different from the adult circulation: the portal branch from umbilical vein vascularises the left lobe with a hight level oxygenated blood, whereas the right hepatic lobe receives blood with low saturation level from the portal vein. During the foetal period, the liver is a hematopoietic organ between 6 and 8 weeks of 
gestation, the right liver has a hematopoietic activity higher than the left lobe [11]. This anatomic difference disappears during the neo-natal period. However, to our knowledge, there is no study dedicated to the analysis of the rhythm of liver growth, and of liver morphology between 3 and 13 years old.

Cadaver data are hard to obtained for children. Liver autopsy studies have also an uncertainty due to the blood flow increasing in vivo volume of the organ; the morphologic description does not consider the liver in anatomic position, which is winded around the vertebral column in right hypochondrium [5].

Few studies have been devoted to the abdominal organ modeling and biometric evolution in children. Nevertheless, based on a previous validated study on child spleen [9], CT-scan data could be used in order to characterize the geometry of child liver.

The objective of the present work is to evaluate the geometrical evolution of the liver and its position in the abdomen during the child growth. The intrinsic morphology like right lobe and left lobe relationship was investigated. Moreover, this study allows comparing liver measurements validated in adults with measurements in children.

\section{MATERIALS AND METHODS}

\section{Sample}

Twenty-five CT scans of maximum 1-mm-thick liver slices have been obtained from children belonging to the paediatric traumatic intensive care unit of the Northern Hospital of Marseille. These data were collected using a helicoidally recording X-ray scanner, SOMATOM Sensation 64 equipment (Siemens Medical ${ }^{\circledR}$ ). CT-scans were performed only for clinical purpose but neither in an investigative setting with normal subjects; they were only collected and anonymized, in accordance with the ethical recommendations. Scans of liver slices either thicker than $1 \mathrm{~mm}$ or not sufficiently injected with iodized contrast agent were found to be not 
discriminating and were rejected. The injection time was varied from one patient to another

\section{Modeling}

The 3D reconstruction of the liver was performed using the Mimics ${ }^{\circledR}$ software (Materialise Software, Brussels) with a semi-automatic recording allowing acceptable reproducibility. The operator chose a specific area of the hepatic parenchyma and the Mimics software selected automatically in vicinity of this specific area pixels having Hounsfield Unit (HU) density of +/- 20 to $30 \mathrm{HU}$ depending on the quality of CT scans. The connectivity index was set on 4 and the selection was accomplished slice by slice. The contour of the selected area was determined manually by the operator mostly around intercostals muscles, pancreas head, inferior cave vein and myocardium at the dome level with similar HU densities very often in direct contact. Then, a 3D model of livers was elaborated by the Mimic ${ }^{\circledR}$ Software from these selected liver regions slice by slice. The calculation parameters from this modeling were of optimal quality. To maintain the reproducibility of measurements the liver pedicle, in particular the portal vein was not included in the calculation of the liver volume. The mask limit chosen for the modeling of the hepatic hilium level corresponded to the separation between the right and left branches of the portal vein. The major objective was to reduce the discrepancy from one operator to another one. 


\section{Measurements}

\section{Liver size}

First, fourteen anatomical points have been defined on the liver in order to characterize its geometry. The position of these points on liver is indicated in Figs.1 and 2. Eleven anatomical points over 14 points were clearly identified on CT liver scans. The localization of 3 anatomical points (M104, M105 and M110) was rather difficult on CT scans since the triangular ligaments and Arantius ligament cannot be visualized clearly.

The center of the superior plateau of the vertebral body of the $11^{\text {th }}$ thoracic vertebra (T11) was adopted as anatomical point on the body skeleton. This vertebra was chosen since there is a narrow relationship between the $11^{\text {th }}$ costal bone and liver. In addition, the interest of this anatomical point was demonstrated in a previous study dealing with the determination of the spleen position in abdominal cavity [9].

Then, geometrical dimensions of the liver have been determined with respect to these anatomical points. The value of nine distances was deduced (Table 2). A local hepatic reference point (corresponding to the anatomical point M000) was used as origin of a frame for these measurements. These nine distances were selected since they are very representative of the external morphology of liver (Figs. 3 and 4).

Furthermore, the values of two angles A-T11 and A-M111 were deduced from the position of the anatomical points. The top of angle A-T11 was on the centre of the superior plateau of the $11^{\text {th }}$ thoracic vertebra. This angle was defined by two linear segments joining the centre of the superior plateau with the superior point of the right rim of the right liver lobe and the left end of the left liver lobe. This angle was selected for the evaluation of the liver, which is winded around the vertebral column.The top of the second angle A-M111 was located on the hepatic dome and the angle was defined by two linear segments connecting the hepatic dome to the superior point of the right rim of the right lobe and the left end of the left lobe. The angle A- 
M111 provided information on the overall morphology of the superior part of liver. The more

\section{Anatomical correlations}

The liver position was determined with respect to a skeleton reference point. The height of the liver into the skeletal system was expressed by the distance between the height of the superior plateau of T11 (corresponding to the coordinate y in the frontal plane) and the height of three anatomical points: M000 (superior point of the junction between the falciform ligament, the right triangular ligament and the right lobe), M001 (right superior extremity of the right lobe), and M101 (left extremity of the left lobe). The reference used for this measurement is the level of the slice on the CT-scan (coordinate "y" of point M and coordinate "y" of T11).

\section{Volume measurements}

Two volume values, the total volume of liver and volume of the right lobe, were deduced from the 3D model given by the Mimics ${ }^{\circledR}$ Software. In addition, the volume ratio defined as the right lobe volume divided by the total liver volume, was also calculated. 


\section{Statistical Analysis}

The intra-operator reproducibility was investigated to evaluate the uncertainty caused by operator for the organ reconstruction from the tomodensitometric slices. This study was achieved from 5 livers reconstructed twice by one operator over two weeks. The sample was composed of 3 boys and 2 girls of 2 to 11 years old. The values of the total liver volume, distances and angles were then compared]. The inter-operator reproducibility was determined for two previous studies on kidney and spleen [9]. Therefore, this reproducibility was not yet evaluated for the liver.

The Kruskal-Wallis test was used to determine whether there were significant differences between the female and the male groups, and between the age groups for the calculated parameters (p-value below 5\%).

Box plots were used to represent maximum, minimal, medium and quartile values for each children groups (A to C).

\section{RESULTS}

Twenty-five CT scans have been investigated with creation of masks for 3D modeling; 825 coordinates of 275 anatomical points have been determined for the calculation of 225 distances, 50 angles and 75 heights. In addition, 50 values of liver total volume and right lobe volume were obtained using the Mimics ${ }^{\circledR}$ software.

\section{Reproducibility of measurements and modeling}

The results obtained from the intra-operator repeatability investigation validated the modeling approach. The systematic uncertainty of two tested measurements, namely liver volume and distance was negligible (Table 3). Therefore, the reproducibility was found to be very high for volume and distance values $(\mathrm{p}=0,938)$. 


\section{Gender influence}

Twenty five children have been selected for this study, i.e., 17 boys and 6 girls. No significant difference between boy and girl groups was detected for the distance, volume and angle values $(\mathrm{p}>0,061)$.

\section{Volume versus children age}

The total volume of liver increased progressively from group A to $\mathrm{C}$, i.e., with increasing children age (Fig.5). The average liver volume values for children belonging to group A to C are given in Table 4.

The ratio between the volume of the right lobe and the total liver volume was rather stable and equal to : (i) 0.777 for children from group A (minimum : 0.727, maximum : 0.853 , standard deviation : 0.043), (ii) 0.764 for children from group B (minimum : 0.639, maximum : 0.832, standard deviation : 0.056), and (iii) 0.809 for children from group C (minimum : 0.729, maximum : 0.848, standard deviation : 0.032) (Fig.5).

\section{Distance versus children age}

The anatomical points were defined a wireframe model to determine the distance values. Seven distance values, D03 to D06, D08, D09 and D17 increased with increasing children age (Fig.5). Two distance values D07 and D10 (Left height of the right lobe and right height of the left lobe) were found to be stable (Fig.5).

\section{Angle and liver height with respect to T11 versus children age}

The value of angle between T11 and two ends (right and left extremities) of liver was stable. The values of this angle A-T11 for children from group A to C are given in table 5 . 
The value of the angle A-M111 between the dome and two liver extremities was observed to be stable during the growth of children. The values of this angle for children belonging to group A to $\mathrm{C}$ are given in table 5 .

The height of liver with respect to the position of T11 did not vary significantly as a function of the children age. In addition, the position of liver with respect to vertebral column did not change during the children growth.

\section{DISCUSSION}

The scannographic investigation of soft organs, like spleen in children was previously evaluated in terms of repeatability and intra-operator reproducibility [9]. The results obtained from the present study of children livers contributed to validate the method based on the determination of masks by Mimics ${ }^{\circledR}$ software and coordinates of anatomical points used as reference points.

The liver volume was found to increase linearly as a function of the children age. A number of formulae for calculation of liver volume as a function of various parameters such as body surface area, sex and age have been proposed in previous works [8]. The approach more often recommended for calculation of liver volume in children of less than 18 years old implied the body surface area [14]. The growth of children liver appeared to be proportional to the staturo-weight growth of patients.

The average liver volume in adults is known to be approximately $1500 \mathrm{~cm}^{3}$. Therefore, one can conclude that the liver continues to grow in children beyond the age of 13 years. The liver volume determined by echography was also found to increase linearly with increasing children height and various diagrams were proposed to evaluate the liver size as a function of the children height [10]. Our results are in accordance with these previous studies: they show tendencies of a linear growth. 
The ratio between the volume of the right lobe and the total liver volume determined in the present work was stable. The volume of the right lobe was equal to $80 \%$ of the total liver volume for the three groups of children investigated. Furthermore, the foetal liver appears to be symmetric, i.e., the volumes of the left and right lobes are similar. The data on the liver growth of foetus have been collected by autopsy studies and foetal in vivo magnetic resonance image (MRI) investigation [3]. The morphology of liver in adults exhibits a volume of the right lobe higher than the left lobe. So, ours results tends to show that this ratio is obtained earlier for children older than about 2 years old. Nevertheless, additional investigations in children of less than 2 years old would be of interest for the analysis of the differential growth of right and left lobes.

The distance measurements performed in the present work have demonstrated that 7 distances increased with the age while two distances, namely the left height of the right lobe (D07) and right height of the left lobe (D10) are constant or stable. These stable distances correspond to the insertion zone of the falciform ligament composed of two peritoneal layers originating from the reflection of the hepatic visceral peritoneum over the diaphragmatic peritoneum. Close to the anterior edge of liver, the falciform ligament contains the round ligament, remaining of the umbilical vein. This area is in front of the anteroposterior left sulcus of the inferior side of liver. This sulcus contains in the anterior part, the round ligament, then the anterior part of the left portal branch and in the posterior part, the Arantius ligament. In foetus, the Arantius vein channel is a connection between the umbilicus vein (venus return placentaire) through the anterior part of the left portal branch and the right posterior cardinal vein, which is the future inferior cave vein.

The umbilical vein and venus channel of Arantius become blocked for the first days of life by a thrombosis caused by the disappearance of the umbilical circulation. Only the part of the left 
portal branch remains permeable. The umbilical vein is converted into round ligament and Arantius channel into Arantius ligament [5].

According to the present work, the liver growth is more limited in front of the falciform ligament. This result can be due to the presence of fibrous embryonic remaining (round ligament and Arantius ligament), which limits the expansion of the hepatic parenchyma in this zone. The growth of liver appears to be progressive and harmonious with respect the right lobe and left lobe volume ratios. By contrast, the liver growth is disharmonious in terms of distances from the falciform ligament.

The liver height at the falciform ligament appears to increase less rapidly with respect to other distances such as right height of the right lobe, horizontal length of liver, diagonal length of liver, horizontal length of the left lobe and thickness of liver.

In a previous study on the anatomy of liver in adults, the liver diameter in the sagittal plane at the falciform ligament was found to be much lower than the diameter at the middle of the right lobe and left lobe in the sagittal plane. This result may validate the hypothesis of a weaker growth of the hepatic parenchyma in this zone [13]. Nevertheless, the results obtained in children can be not totally valid since the number of children investigated was relatively low.

The two angles measured on 25 scanners were very similar for the three groups of children investigated. The angle T11 with the summit on the superior plateau of T11 was not modified during the growth. The right lobe is winded around the vertebral column and filled out almost completely the right hypochondrium. The position of the left end of the left lobe is not changed during the growth and remains in front of the stomach.

The angle A-M111 remains also stable.So, the overall morphology of the liver seems to be not modified during the growth. Nevertheless, an uncertainty in the determination of this angle may arise from the displacement of liver caused by respiratory movements. The position of 
liver with respect to T11 is stable during the growth. The liver possesses several fixation elements; the principal element is the inferior vena cava through short sus-hepatic veins. In addition, peritoneal ligaments contribute to the liver fixation, namely the falciform, the coronary ligament containing one anterosuperior layer and an inferior layer corresponding to lateral ends of the coronary ligament.

\section{CONCLUSION}

The anatomic modeling of liver in children from CT scans using the Mimics ${ }^{\circledR}$ software was validated by results obtained from the present work. These measurements were of interest for the analysis of liver growth, which appears to be harmonious with respect to the ratio between the volumes of right and left lobes and disharmonious in terms of distances situated in relation to the falciform ligament. The position of liver in the peritoneal cavity with respect to the vertebral column was not modified during the growth of children. These results would be improved by a prospective investigation of a large group of children of less than 2 years old. The major objective of this study would be the complete numerical modeling of virtual children in the framework of a French project "SECUR-ENFANT" which aims to simulate the biomechanical behaviour of the children during a road accident.

\section{ACKNOWLEDGEMENTS}

This work was partly funded by the French National Research Agency (ANR) in the framework of the "SECUR_ENFANT" project.

\section{ETHICAL STANDARDS}

The experiments comply with the current laws of the country in which they were performed.

\section{CONFLICT OF INTEREST}

The authors declare that they have no conflict of interest. 


\section{REFERENCES}

1 Behr, M., Arnoux, P.J., Serre, T., Bidal, S., Kang, H.S., Thollon, L., Cavallero, C., Kayvantash, K., \& Brunet, C. (2003). A human model for road safety : from geometrical acquisition to model validation with radios. Computer Methods on Biomechanics and Biomedical Engineering 6(4):263-273.

2 Beusenberg, M.C., Happee, R., Twisk, D., \& Janssen, E.G. (1993). Status of injury biomechanics for the development of child dummies. Paper presented at the Child Occupant Protection Symposium. San Antonio, Texas, USA.

3 Brugger, P.C., Prayer, D. (2006). Imagerie par résonance magnétique de l'abdomen fetal. EMC (Elsevier Masson SAS, Paris), Radiodiagnostic - Appareil digestif, 33-000-A-20.

4 Caix, M., Outrequin, G., \& Cubertafond, P. (1970). Contribution à l'étude des variations morphologiques du foie en fonction de l'ontogénèse. Bull Association Anatomy $149: 692-712$.

5 Castaing, D., Veilhan, L.A. (2006). Anatomie du foie et des voies biliaires. EMC (Elsevier SAS, Paris), Techniques chirurgicales - Appareil digestif. 40-760.

6 Champetier, J. (1994). Le foie. In : Chevrel JP. Anatomie Clinique (2) Le tronc. 389405.

7 Cheynel, N., Serre, T., Arnoux, P.J., Braque, P., Benoit L., Berdah, S.V., Brunet, C. (2006). Biomechanic study of the human liver during a frontal deceleration. Journal of Traumatology. 61, 855-861.

8 Chouker, A., et al. (2004) Estimation of liver size for liver transplantation : the impact of age and gender. Liver Transplantation. 10, 678-685. 
9 Coquet, B., Sandoz, B., Savoie, P.H., Serre, T., Thollon, L., Brunet, C.

Anthropometric Characterization Of Spleen In Children. Surgical and Radiologic Anatomy. In press. DOI 10.1007/s00276-009-0535-6.

10 Dittrich, M., Milde, S., Dinkel, E., Baumann, W., N'sitzel, D. (1983). Sonographic biometry of liver and spleen size in chilhood. Pediatric Radinlogy, 13, 206-211.

11 Emery, J.L. (1963). Functional asymmetry of the liver. Ann N Y Academic Sciences, $111,37-44$

12 Johnson, T., Tucker, G., Tanner, M. (2005). Changes in liver volume from birth to adulthood: a meta-analysis. Liver Transplantation. 11, 1481-1493.

13 Rosset, E., Brunet, C. (1995). Anatomic basis of the liver for the development of a perihepatic prosthesis. Surgical Radiologic Anatomy.17 (1):1-5.

14 Vauthey, J., Abdalla, E., Doherty, D., Gertsch, P., Fenstermacher, M., Loyer, E., Lerut, J., Materne, R., Wang, X., Encarnation, A., Herron, D., Mathey, C., Ferrari, G., Charnsangave, C. (2002). Body surface area and body weight predict total liver volume in Western adults. Liver Transplantation. 8, 233-240. 


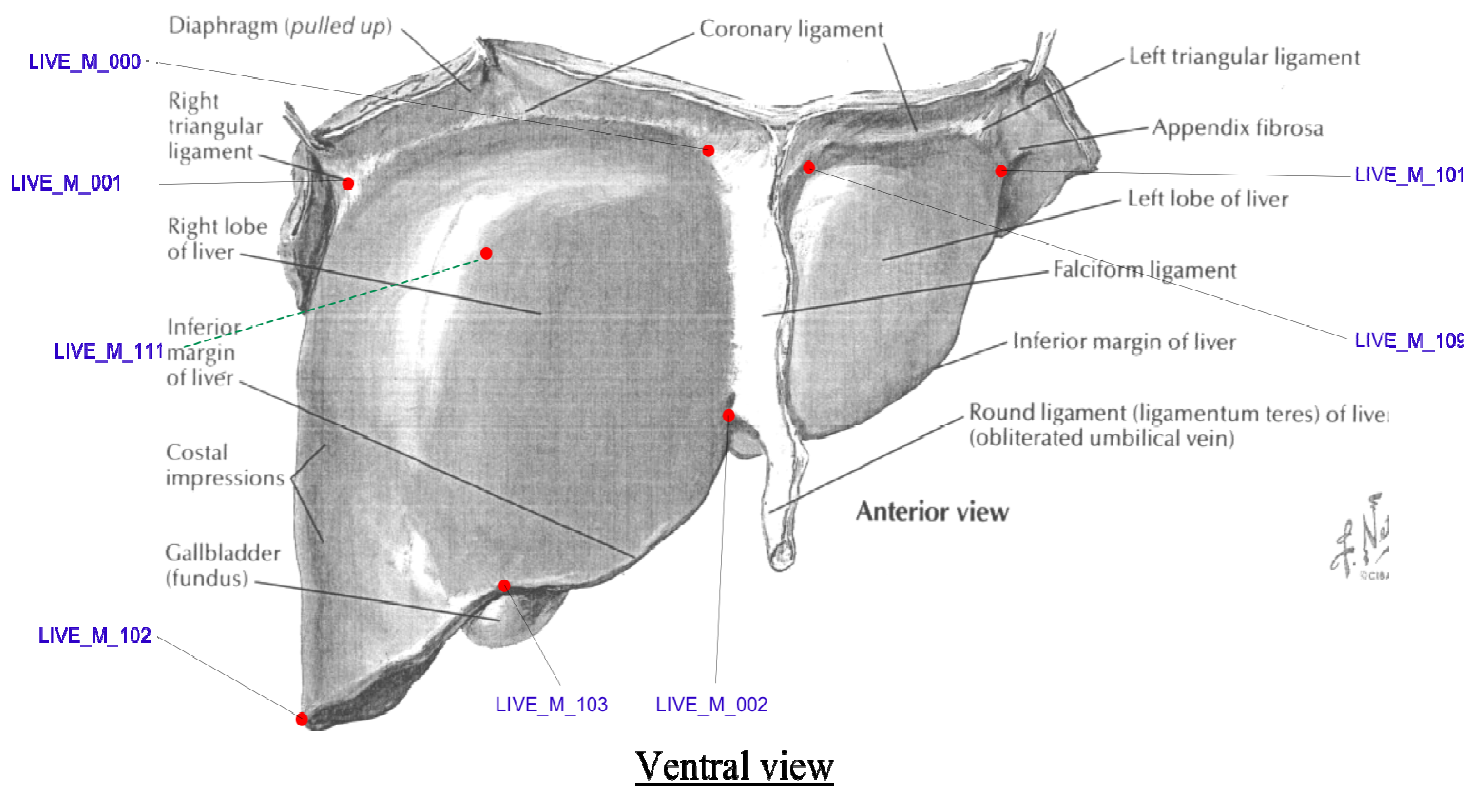

Figure 1: Reference points HUMOS on the ventral view of the liver (modified according to Netter) 


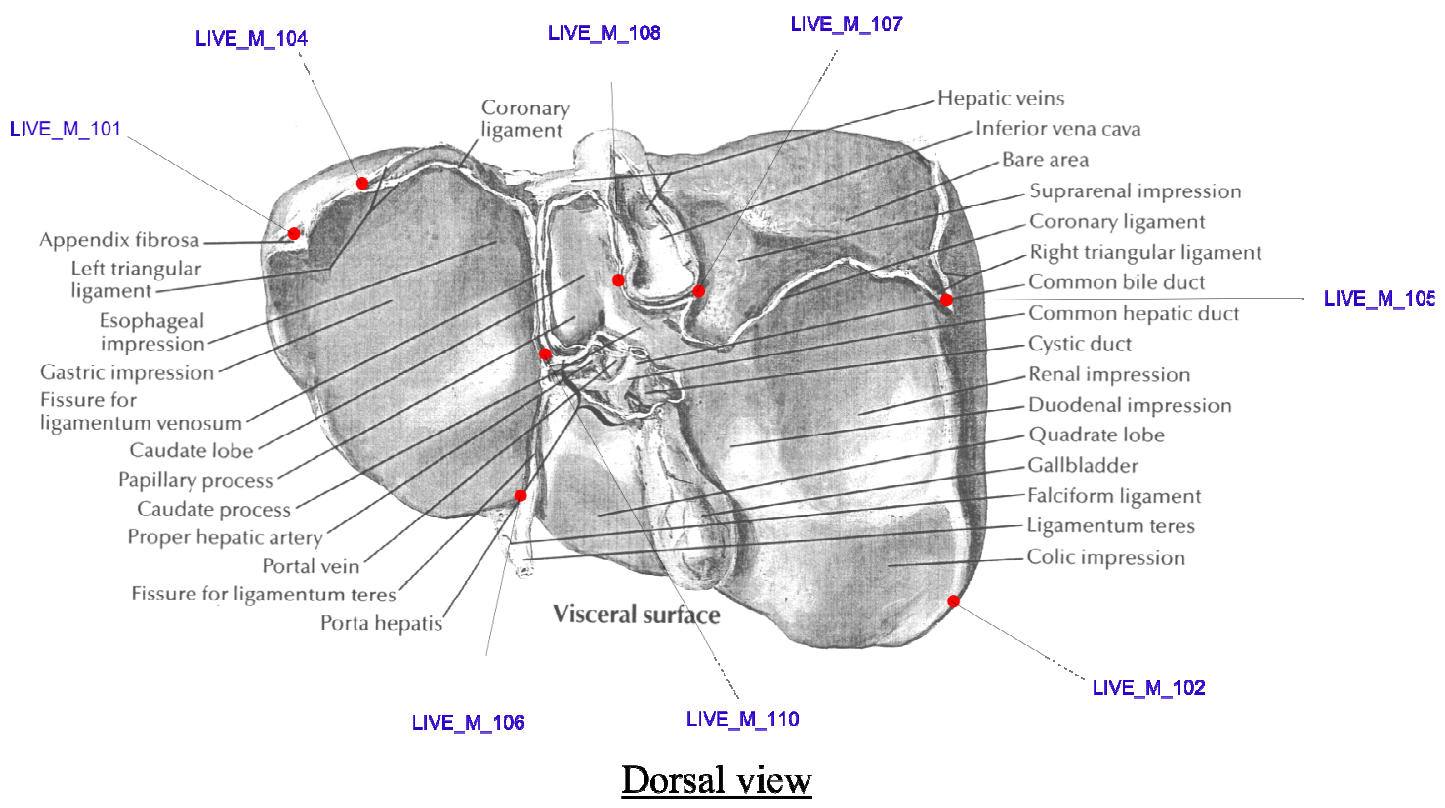

Figure 2: Reference points HUMOS on the dorsal view of the liver (modified according to Netter) 


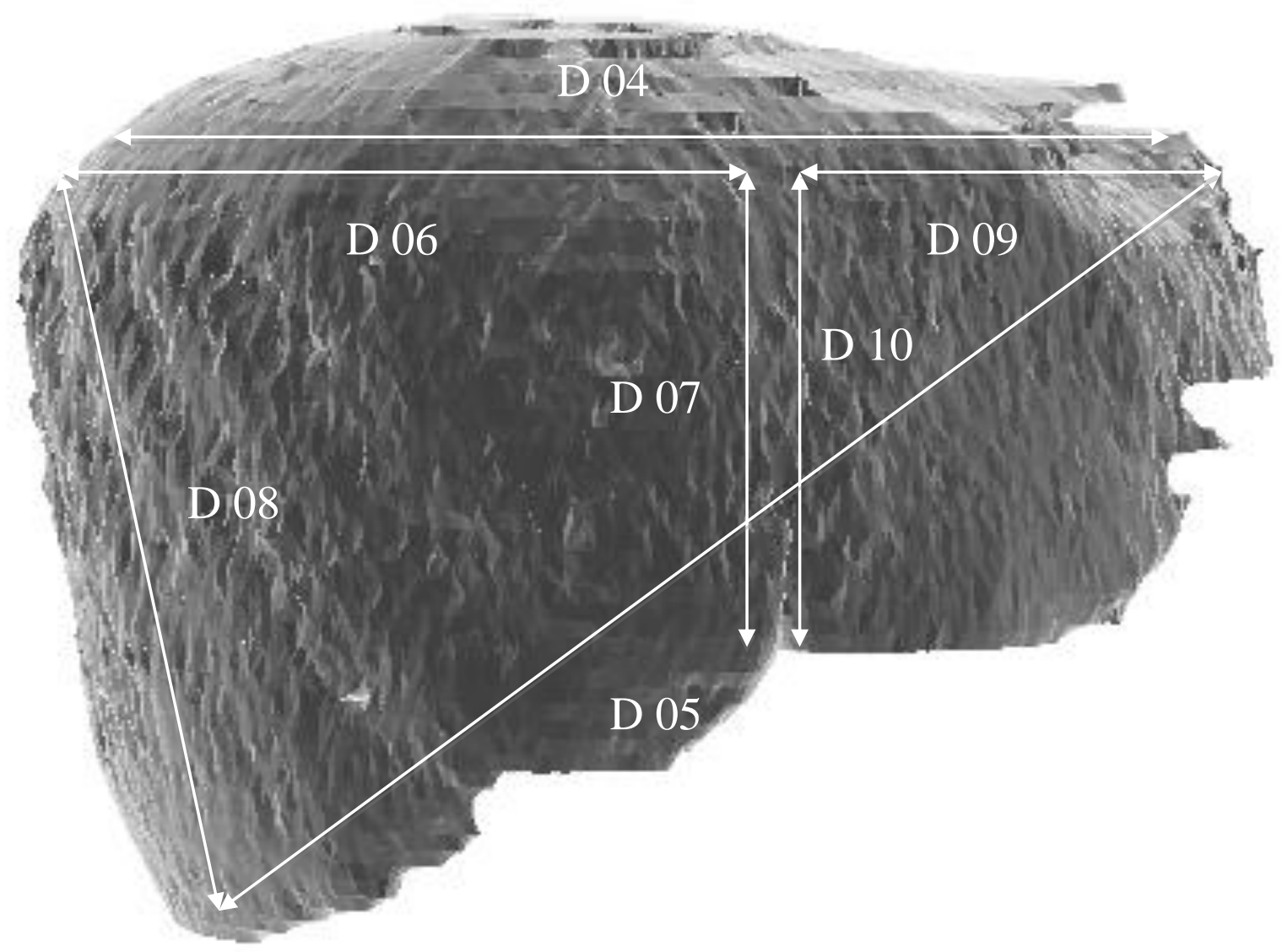

Figure 3: 4 years old liver 3D model (ventral view) and distances D04, D05, D06, D07, D08, D09, D10. 


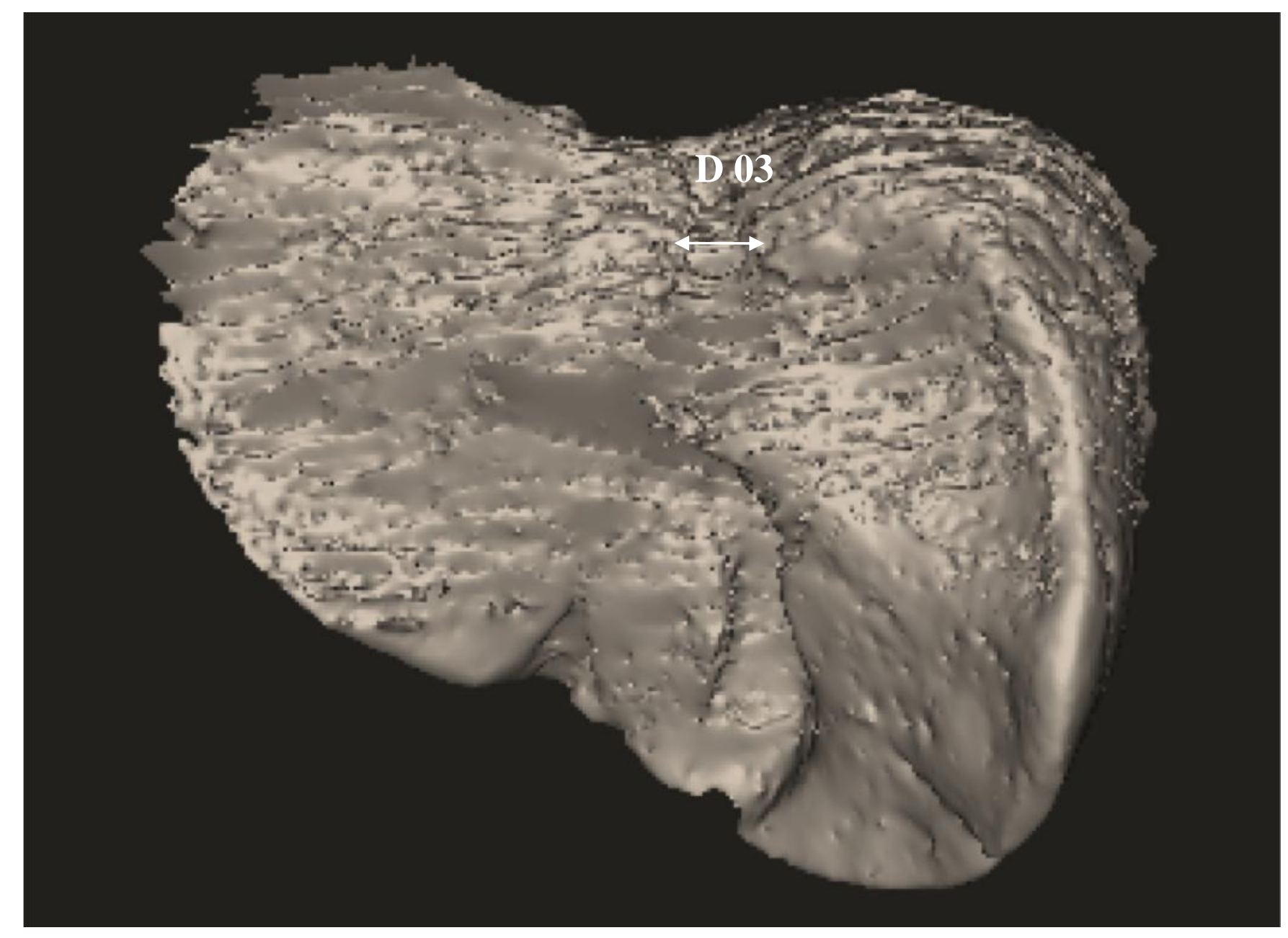

Figure 4: 4 years old children liver 3D model (dorsal view) and distance D03. 


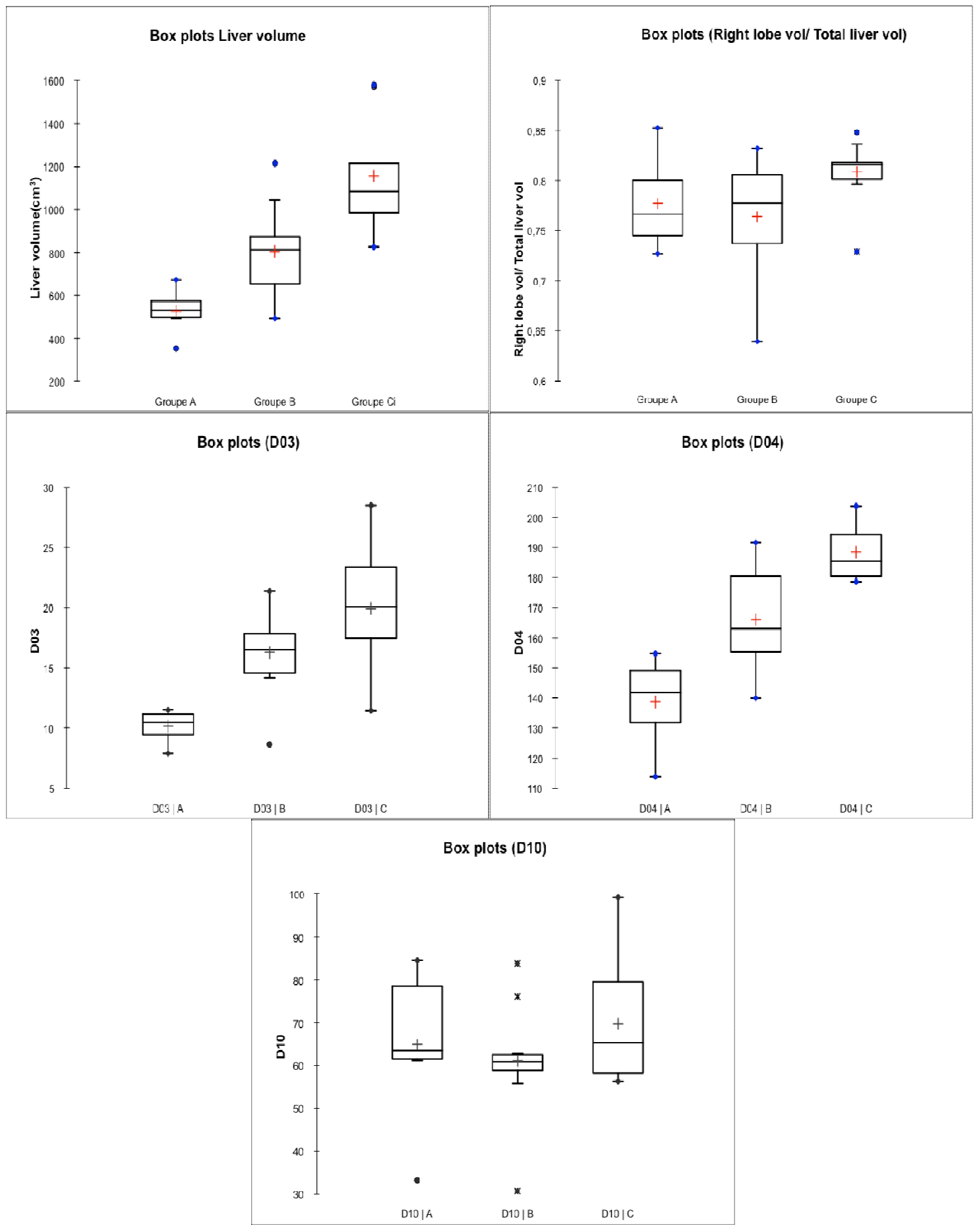

Figure 5: Anthropometric parameters according to the age group (Liver volume, Right lobe volume / Total liver volume, Distances D03, D04 and D10). 
Table 1: Anatomic reference points HUMOS.

\begin{tabular}{|l|l|}
\hline CODE & Definition \\
\hline LIVE_M_000 & $\begin{array}{l}\text { Superior point of the junction between the falciform ligament, the right } \\
\text { triangular ligament and the right lobe }\end{array}$ \\
\hline LIVE_M_001 & Right Superior extremity of the right lobe \\
\hline LIVE_M_002 & $\begin{array}{l}\text { Right inferior point of the junction between the falciform ligament and the right } \\
\text { lobe }\end{array}$ \\
\hline LIVE_M_101 & Left extremity of the left lobe (appendix fibrosa) \\
\hline LIVE_M_102 & Right inferior extremity of the right lobe \\
\hline LIVE_M_103 & Most inferior point of the engthdder impression \\
\hline LIVE_M_104 & Left extremity of the left triangular ligament \\
\hline LIVE_M_105 & Right extremity of the right triangular ligament \\
\hline LIVE_M_106 & Inferior point of the junction between the round ligament and the left lobe \\
\hline LIVE_M_107 & $\begin{array}{l}\text { Right point of the inferior junction between the inferior vena cava (IVC) and the } \\
\text { right lobe }\end{array}$ \\
\hline LIVE_M_108 & $\begin{array}{l}\text { Left point of the inferior junction between the inferior vena cava (IVC) and the } \\
\text { right lobe }\end{array}$ \\
\hline LIVE_M_109 & $\begin{array}{l}\text { Superior point of the junction between the falciform ligament, the left triangular } \\
\text { ligament and the left lobe }\end{array}$ \\
\hline LIVE_M_110 & Inferior point of the fissure for ligamenum venosum \\
\hline LIVE_M_111 & Hepatic dome \\
\hline
\end{tabular}


Table 2: HUMOS measurements.

\begin{tabular}{|l|l|l|}
\hline CODE & Definition & Code of control points needed \\
\hline LIVE_D_03 & Diameter of the inferior vena cava (IVC) & LIVE_M_107, LIVE_M_108 \\
\hline LIVE_D_04 & Horizontal length of the liver & LIVE_M_101, LIVE_M_001 \\
\hline LIVE_D_05 & Oblique length of the liver & LIVE_M_101, LIVE_M_102 \\
\hline LIVE_D_06 & Horizontal length of the right lobe & LIVE_M_001, LIVE_M_000 \\
\hline LIVE_D_07 & Left height of the right lobe & LIVE_M_002, LIVE_M_000 \\
\hline LIVE_D_08 & Right height of the right lobe & LIVE_M_001, LIVE_M_102 \\
\hline LIVE_D_09 & Horizontal ength of the left lobe & LIVE_M_101, LIVE_M_109 \\
\hline LIVE_D_10 & Right height of the left lobe & LIVE_M_106, LIVE_M_109 \\
\hline LIVE_D_17 & Thickness of liver & LIVE_M_000, LIVE_M_108 \\
\hline
\end{tabular}


Table 3: Intra-operator repeatability.

\begin{tabular}{|l|c|c|c|}
\hline Differences & Volumes $\mathbf{( c m 3 )}$ & Distances $\mathbf{( m m}$ ) & Angles $^{\circ}$ ) \\
\hline Mean & 2.95 & 6.3 & 6.4 \\
\hline SD & 3.7 & 5.6 & 7.5 \\
\hline
\end{tabular}


Table 4: Liver volume for each group.

\begin{tabular}{|l|c|c|c|}
\hline & Group A & Group B & Group C \\
\hline Children age (years) & $2-5$ & $6-9$ & $10-13$ \\
\hline Mean liver volume $\left.\mathbf{( c m}^{\mathbf{3}}\right)$ & 527 & 804 & 1156 \\
\hline Minimum $\left(\mathbf{c m}^{\mathbf{3}}\right)$ & 352 & 492 & 825 \\
\hline Maximum $\left(\mathbf{c m}^{\mathbf{3}}\right)$ & 673 & 1215 & 1539 \\
\hline Standard deviation & 97 & 211 & 251 \\
\hline
\end{tabular}


Table 5: Angle data for each group.

\begin{tabular}{|l|c|c|c|}
\hline & Group A & Group B & Group C \\
\hline Children age (years) & $2-5$ & $6-9$ & $10-13$ \\
\hline Mean angle T11 & $95^{\circ}$ & $84^{\circ}$ & $90^{\circ}$ \\
\hline Minimum angle T11 & $80^{\circ}$ & 63 & $76^{\circ}$ \\
\hline Maximum angle T11 & $116^{\circ}$ & $101^{\circ}$ & $112^{\circ}$ \\
\hline Standard déviation T11 & 12.3 & 11.6 & 10.9 \\
\hline Mean angle M111 & $140^{\circ}$ & $139^{\circ}$ & $138^{\circ}$ \\
\hline Minimum angle M111 & $119^{\circ}$ & $125^{\circ}$ & $149^{\circ}$ \\
\hline Maximum angle M111 & $150^{\circ}$ & $150^{\circ}$ & 4.9 \\
\hline Standard déviation M111 & 11.0 & 7.3 & \\
\hline
\end{tabular}

